\title{
OPEN Urban storm water infiltration systems are not reliable sinks for biocides: evidence from column experiments
}

\author{
Marcus Bork ${ }^{1,2 \bowtie}$, Jens Lange ${ }^{1}$, Markus Graf-Rosenfellner ${ }^{2}$, Birte Hensen $^{3}$, Oliver Olsson ${ }^{3}$, \\ Thomas Hartung ${ }^{2}$, Elena Fernández-Pascual ${ }^{3,4}$ \& Friederike Lang ${ }^{2}$
}

Groundwater quality in urban catchments is endangered by the input of biocides, such as those used in facade paints to suppress algae and fungal growth and washed off by heavy rainfall. Their retention in storm water infiltration systems (SIS) depends, in addition to their molecular properties, on chemical properties and structure of the integrated soil layer. These soil properties change over time and thus possibly also the relevance of preferential flow paths, e.g. due to ongoing biological activity. To investigate the mobility of biocides in SIS, we analyzed the breakthrough of differently adsorbing tracers (bromide, uranine, sulforhodamine B) and commonly used biocides (diuron, terbutryn, octhilinone) in laboratory column experiments of undisturbed soil cores of SIS, covering ages from 3 to 18 years. Despite similar soil texture and chemical soil properties, retention of tracers and biocides differed distinctly between SIS. Tracer and biocide breakthrough ranged from $54 \%$ and $5 \%$, to $96 \%$ and $54 \%$, respectively. We related the reduced solute retention to preferential transport in macropores as could be confirmed by brilliant blue staining. Our results suggest an increasing risk of groundwater pollution with increasing number of macropores related to biological activity and the age of SIS.

Urban storm water management concepts such as green infrastructure (GI) have become increasingly implemented worldwide for their numerous environmental benefits ${ }^{1-4}$. One example of GI is local infiltration of urban storm water that, in Germany, is required by the German federal water law ${ }^{5}$ due to benefits for micro-climate ${ }^{6}$ and urban hydrology such as reducing storm water quantity ${ }^{7,8}$, restoring groundwater levels ${ }^{9-11}$ and relieving sewer systems ${ }^{12}$. However, the direct infiltration of urban storm water could lead to groundwater pollution since storm water may be loaded with nutrients ${ }^{13}$, heavy metals ${ }^{14,15}$ and organic pollutants such as hydrocarbons ${ }^{16,17}$ and pesticides ${ }^{18-20}$. Recently, biocides used in facade renders and paints to suppress algae and fungal growth ${ }^{21}$ are receiving increasing attention as they can be washed off from facades by heavy rainfall ${ }^{22-25}$. This biocide wash-off occurs during entire rain events ${ }^{26}$, depends on the conditions of the rainfall and on transport processes within the facade material ${ }^{27}$ and happens even fourteen years after painting of the facade ${ }^{28}$.

Biocide-loaded storm water either infiltrates into the soil around houses ${ }^{29}$ or is directed into SIS such as swales and swale-trench-systems. Together with local infiltration of storm water, the purpose of SIS is to reduce moderate contaminant load ${ }^{30,31}$. Reviews of ${ }^{17}$ and $^{32}$ showed that this may be the case for hydrocarbons or pesticides. However ${ }^{28}$, recently showed that SIS could be pathways for biocides and their transformation products into groundwater. Consequently, further research is needed on factors that may favor the leaching of organic pollutants in SIS.

Generally, the uppermost layer of swales and swale-trench-systems consists of topsoil material ${ }^{33}$. In these layers, organic pollutants such as biocides may be retained by similar processes as in natural soils: transformation, mineralization, plant uptake and sorption (in the following we will call the uppermost soil filter media of SIS only soil). These processes depend on molecular properties of the solutes, on the vegetation cover and on the physical and chemical soil properties such as $\mathrm{pH}$, organic matter $(\mathrm{OM})$ content, texture and structure ${ }^{34}$, which

\footnotetext{
${ }^{1}$ Hydrology, Faculty of Environment and Natural Resources, University of Freiburg, 79098 Freiburg, Germany. ${ }^{2}$ Soil Ecology, Faculty of Environment and Natural Resources, University of Freiburg, 79098 Freiburg, Germany. ${ }^{3}$ Institute of Sustainable and Environmental Chemistry, Leuphana University Lüneburg, 21335 Lünbeburg, Germany. 'Environmental Research Institute, University College Cork, Cork T23 XE10, Ireland. ${ }^{\boxplus e m a i l: ~ m a r c u s . b o r k @ h y d r o l o g y . u n i-f r e i b u r g . d e ~}$
} 

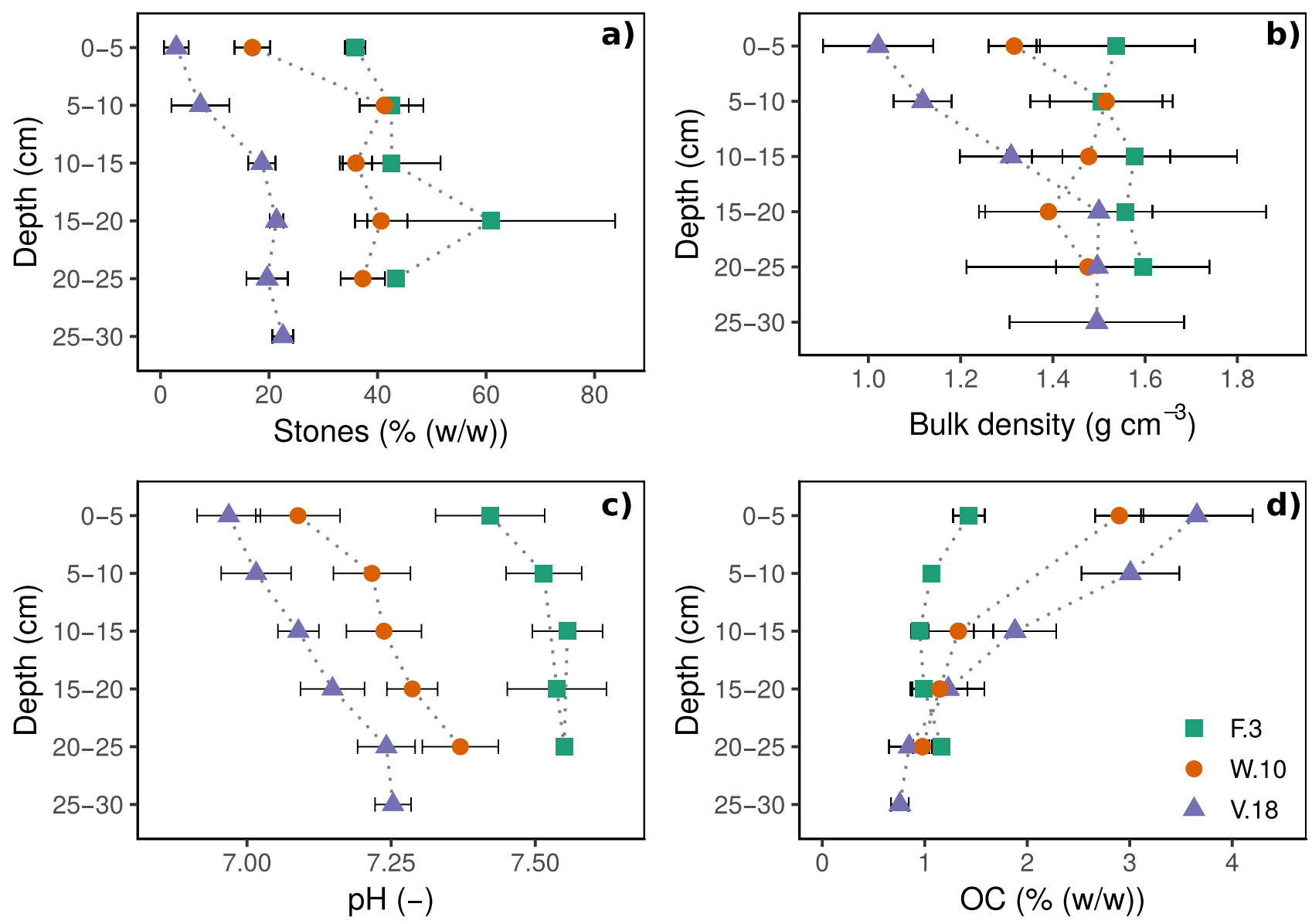

Figure 1. Depth-dependent soil properties: (a) stone content [\% (w/w)], (b) bulk density $\left(\mathrm{g} \mathrm{cm}^{-3}\right),(\mathbf{c}) \mathrm{pH}$ $\left(0.01 \mathrm{M} \mathrm{CaCl}_{2}\right)$ and $(\mathbf{d})$ organic carbon content $(\mathrm{OC})[\%(\mathrm{w} / \mathrm{w})]$ of the three sites F3, W.10, V18. The error bars are the standard deviation $(\mathrm{n}=4)$.

change with time. Furthermore, the retention can be limited by the formation of preferential flow paths. Evidence regarding the relevance of these different processes is missing so far.

Typically, soil pores are clogged by the entry of suspended solids with storm water ${ }^{35}$ thus reducing water infiltration. Nevertheless, the hydraulic efficiency of SIS has been reported to be maintained even after longterm operation ${ }^{8,33,36}$. To the best of our knowledge, no study has systematically addressed this contradiction so far. One explanation could be an increased number of preferential flow paths due to root growth and other biological activity that compensates for soil pore clogging. Yet preferential flow paths induce solute transport ${ }^{37}$ as observed for pesticides in agricultural soils ${ }^{38,39}$. Thus, we investigated three SIS with regard to the influence of preferential flow paths on the transport of biocides.

We analyzed the depth distributions of physical and chemical soil properties and conducted laboratoryscale percolation experiments using undisturbed soil core samples from three SIS established 3, 10 and 18 years ago (F.3, W.10 and V.18). In these experiments we investigated the breakthrough of three commonly used biocides $^{29}$, 40: diuron (3-(3,4-dichlorophenyl)-1,1-dimethylurea), terbutryn (N2-tert-butyl-N4-ethyl-6-methylsulfanyl-1,3,5-triazine-2,4-diamine), and OIT (2-octyl-1,2-thiazol-3-one). Furthermore, we applied a tracer mix of non-adsorbing bromide $\left(\mathrm{Br}^{-}\right)$and chloride $\left(\mathrm{Cl}^{-}\right)$, together with the variously adsorbing fluorescent dyes uranine (UR) and sulforhodamine B (SRB) that are often used to investigate preferential flow ${ }^{41-44}$. With this multi-tracer approach and a staining of the soil column using brilliant blue, we aimed to investigate pollutant retention capacity of different SIS.

\section{Results and discussion}

Soil properties. Stone content. The stone content ranged from $15 \pm 8 \%(\mathrm{w} / \mathrm{w})$ at V.18 to $44 \pm 13 \%(\mathrm{w} / \mathrm{w})$ at F.3 (Fig. 1a, Table 1). These differences between sites may partly be due to different sources of the raw material used to create the SIS. Further, the stone content increased with depth within the first $15 \mathrm{~cm}(\mathrm{~V} .18)$ and $10 \mathrm{~cm}$ (W.10), but remained approximately constant over depth at F.3. Hence, the stone content in the upper layers of the older SIS (W.10 and V.18) was lower than in the lower layers. These depth-related differences at each site may be related to time-dependent developments within the SIS. In the uppermost layers of V.18 and W.10, stone content was comparatively low probably due to input of fine mineral and organic particles by storm water. For 


\begin{tabular}{|c|c|c|c|c|c|c|c|}
\hline \multirow[b]{2}{*}{ Site.age } & \multirow[b]{2}{*}{ Stones $[\%(w / w)]$} & \multirow[b]{2}{*}{$\mathrm{pH}^{\mathrm{a}}(-)$} & \multirow[b]{2}{*}{ OC [\% (w/w)] } & \multirow[b]{2}{*}{ Bulk density $\left(\mathrm{g} \mathrm{cm}^{-3}\right)$} & Sand & Silt & Clay \\
\hline & & & & & \multicolumn{3}{|c|}{$[\%(w / w)]$} \\
\hline F.3 & $44 \pm 13$ & $7.5 \pm 0.1$ & $1.1 \pm 0.2$ & $1.6 \pm 0.2$ & $80 \pm 2$ & $16 \pm 2$ & $5 \pm 1$ \\
\hline W.10 & $34 \pm 10$ & $7.2 \pm 0.1$ & $1.6 \pm 0.8$ & $1.4 \pm 0.2$ & $73 \pm 4$ & $20 \pm 3$ & $7 \pm 1$ \\
\hline V.18 & $15 \pm 8$ & $7.1 \pm 0.1$ & $1.9 \pm 1.2$ & $1.3 \pm 0.2$ & $57 \pm 7$ & $34 \pm 6$ & $9 \pm 2$ \\
\hline
\end{tabular}

Table 1. Soil properties of SIS. They are calculated as the mean of all depth steps of four soil cores \pm standard deviation. Since the number of depth steps differed between the sites and the number of laboratory repetitions differed, the number of repetitions varied among the methods and the sites ( $\mathrm{pH}: \mathrm{n}=51-69, \mathrm{OC}: \mathrm{n}=17-23$, Stones: $\mathrm{n}=16-22$, Bulk density: $\mathrm{n}=16-22$; for details see Table $\mathrm{S} 4)$. ${ }^{\mathrm{a}} \mathrm{pH}$ in $0.01 \mathrm{M} \mathrm{CaCl}_{2}$.

the oldest SIS (V.18), this assumption is supported by the field observation of soil material lying on a bricked stone border near the inflow within the SIS.

Bulk density. The bulk density in the upper layers of the different SIS increased in the following order: V.18 $<$ W.10 < F.3 (Fig. 1b, Table 1). At V.18, we observed the strongest change with depth from $1.0 \pm 0.1 \mathrm{~g} \mathrm{~cm}^{-3}$ $(0-5 \mathrm{~cm})$ to $1.5 \pm 0.1 \mathrm{~g} \mathrm{~cm}^{-3}(15-20 \mathrm{~cm})$. In contrast, we observed almost no depth-dependent change of bulk density at the youngest site of F.3 $\left(1.6 \pm 0.2 \mathrm{~g} \mathrm{~cm}^{-3}\right)$.

In samples of the older sites of V.18 and W.10, low bulk densities in the uppermost layers compared to deeper layers were probably caused by the activity of macrofauna, an intensive rooting, a higher organic carbon (OC) content and the input of strongly sorted fine material. The older the SIS, the stronger the effect of these factors.

At F.3 the bulk density was relatively high. Here, we supposed an uniform compaction of the soil layer under the topsoil during construction. This assumption was supported by the observation of redox characteristics (iron-red stains next to grey iron-depleted areas) in the soil at approximately $25 \mathrm{~cm}$ depth caused by the lack of oxygen due to accumulating water ${ }^{45}$ in compacted soil.

Texture. The mean texture of fine soil at all SIS was very similar: $57-80 \%(\mathrm{w} / \mathrm{w})$ sand, $16-34 \%(\mathrm{w} / \mathrm{w})$ silt and $5-9 \%(\mathrm{w} / \mathrm{w})$ clay, since similar textured materials were used for construction to guarantee solute retention and sufficient hydraulic conductivity ${ }^{31}$. Average clay contents of all SIS were within acceptable ranges of Best Management Practice (BMP) claimed by ATV-DVWK A-138 $(<10 \%(\mathrm{w} / \mathrm{w}) \text { clay })^{31}$.

The clay fraction at the oldest SIS (V.18) decreased slightly with depth from $12 \%(\mathrm{w} / \mathrm{w}$ ) at $0-5 \mathrm{~cm}$ to $7 \%(\mathrm{w} / \mathrm{w}$ ) at 20-25 cm (Figure S4) while it remained constant with depth at W.10 and F.3. Since a homogeneous texture after SIS construction can be assumed for each SIS, a higher clay content in the uppermost layers suggested fine particle deposition by storm water, as was observed by ${ }^{46}$.

pH. The pH was above 7.0 at nearly all sites and depths (Fig. 1c, Table 1) and was thus within the range of $\mathrm{BMP}^{31}$.

The $\mathrm{pH}$ increased slightly in the following order: V.18 $<$ W.10 $<$ F.3. These slight $\mathrm{pH}$ differences among the SIS could be either due to age (stronger acidification of older soils) or due to different initial $\mathrm{pH}$ values of the topsoil materials.

Furthermore, the $\mathrm{pH}$ increased with depth at all sites, which was stronger at older sites (V.18 and W.10) than at F.3. These larger depth-gradients at older sites indicate a relationship between $\mathrm{pH}$ and age of the sites: older SIS were more acidified in the upper layers than the youngest SIS (F.3) due to the input of acids by precipitation, the production of $\mathrm{CO}_{2}$ by soil respiration and the release of protons and organic acids by roots ${ }^{45}$.

Organic carbon content. The OC content and the slope of depth-gradients within the upper $15 \mathrm{~cm}$ increased from $1.15 \pm 0.3 \%(\mathrm{w} / \mathrm{w})$ at the youngest SIS to $2.85 \pm 0.9 \%(\mathrm{w} / \mathrm{w})$ at the oldest SIS (Fig. 1d, Table 1). This indicates that, in general, OC accumulated during soil development in upper soil layers while the stone content, the bulk density and the $\mathrm{pH}$ decreased. Overall, the OC contents of all SIS were within the BMP ranges ${ }^{31}$.

Soil development and spatial variability. All soil parameters described above and especially the development of depth gradients indicate continuous soil development (alteration of important soil properties such as $\mathrm{pH}$, texture, OC content and distribution) in the investigated SIS due to physical and chemical processes and sediment input with storm water. Consequently, biological activity also increased, as shown by the observation of macrofauna at V.18 (earthworms) and W.10 (ants) while no macrofauna was observed at F.3. Overall, age of SIS is reflected in the soil properties after only a few years.

We assumed that the spatial variability of the soils within each SIS was relatively small, as probably only one material was used to build up the upper soil layer. As described above, a low spatial variability within each SIS was confirmed by the low variability of analyzed soil properties of the soil samples $(n=4)$. Therefore, we assumed in the present study that one soil column with a wide diameter $(20 \mathrm{~cm})$ at each SIS can be considered representative of the SIS inflow area. To determine the influence of flow paths on solute transport we thus considered a column experiment without repetition as sufficient to further investigate the differences between the SIS. This is common for such complex column experiments with undisturbed soils (see e.g. ${ }^{47-49}$ ) since their performance is very time-consuming. 


\begin{tabular}{|c|c|c|c|c|c|c|c|c|c|}
\hline \multirow[b]{2}{*}{ Column (site.age) } & \multirow[b]{2}{*}{$\mathbf{d}_{c o l}(\mathrm{~cm})$} & \multirow[b]{2}{*}{$\mathrm{L}_{c o l}(\mathrm{~cm})$} & \multirow[b]{2}{*}{$\mathrm{PV}_{\text {tot, est }}{ }^{\mathrm{a}}(\mathrm{L})$} & \multirow[b]{2}{*}{ Time (h) } & \multirow[b]{2}{*}{ TPS $^{\mathbf{b}}(\mathrm{L})$} & $\mathbf{q}_{a v^{c}}{ }^{\mathrm{c}}$ & $\mathbf{q}_{\text {min }}{ }^{\mathrm{d}}$ & $\mathbf{q}_{\max }{ }^{\mathrm{c}}$ & $\mathrm{K}_{s}^{\mathrm{e}}$ \\
\hline & & & & & & \multicolumn{4}{|c|}{$\left(\mathrm{cm} \mathrm{h}^{-1}\right)$} \\
\hline F.3 & 20 & 21 & 1.29 & 28.0 & 5.2 & 0.59 & 0.32 & 0.97 & 0.18 \\
\hline W.10 & 20 & 25 & 1.91 & 12.7 & 7.6 & 1.91 & 1.58 & 2.60 & 0.66 \\
\hline V.18 & 20 & 25 & 2.80 & 12.7 & 11.2 & 2.82 & 2.40 & 3.70 & 0.98 \\
\hline
\end{tabular}

Table 2. Soil column properties, water fluxes q [average (av), minimum (min) and maximum ( $\max )$ ] and total percolated water (L) during the column experiment in the three soil columns F3, W.10 and V.18. ${ }^{a} \mathrm{PV}_{\text {tot,est }}$ : estimated total pore volume: estimated from pedotransfer functions according to ${ }^{50}$ and corrected by stone content (see Eq. 1). ${ }^{\mathrm{b}}$ TPS: total percolated biocide/tracer solution (L) after the percolation of four pore volumes. ${ }^{c} \mathrm{q}_{a v}$ is the average water flux through the soil column and is the slope of the linear regression of the outflow (L) over time (h). ${ }^{\mathrm{d}} \mathrm{q}_{\min }$ and $\mathrm{q}_{\max }$ are the lowest and the highest calculated water flux during the column experiment. ${ }^{e}$ Calculated according to Eq. (2) with $\mathrm{q}_{a v}$ and a hydraulic head gradient of $3.2 \mathrm{~cm} \mathrm{~cm}^{-1}$ (F.3) and $2.9 \mathrm{~cm} \mathrm{~cm}^{-1}$ (W.10 and V.18).

Percolation experiment. Saturated hydraulic conductivity and water flux. The saturated hydraulic conductivity $\mathrm{K}_{s}\left(\mathrm{~cm} \mathrm{~h}^{-1}\right)$ differed strongly between the soil columns (Table 2). It was lowest in the youngest SIS F.3 $\left(0.18 \mathrm{~cm} \mathrm{~h}^{-1}\right)$, four times higher at W.10 $\left(0.66 \mathrm{~cm} \mathrm{~h}^{-1}\right)$, and approximately six times higher in the oldest SIS V.18 $\left(0.98 \mathrm{~cm} \mathrm{~h}^{-1}\right)$. Water flow velocities at all sites and time steps were in the optimal range for urban swale systems defined by BMP $\left(0.006 \mathrm{~cm} \mathrm{~h}^{-1}<\mathrm{q}<6 \mathrm{~cm} \mathrm{~h}^{-1}\right)^{31}$.

The water flux decreased continuously with time in all soil columns: in W.10 and V.18 approximately 1.5 times and in F.3 approximately 3 times (Table 2, Figure S7 and Fig. S8). This could be due to clogging of pores in the $0.45 \mu \mathrm{m}$ nylon membrane by colloids ${ }^{51}$ or dissolved organic matter ${ }^{52}$. In our experiment, the existence of colloids was likely as they could be mobilized by a decreased ionic strength of the infiltrating deionized water ${ }^{53}$.

Tracer breakthrough. Breakthrough curves (BTCs) of $\mathrm{Br}^{-}$and $\mathrm{Cl}^{-}$reached $90-100 \%$ at the outlet of all soil columns after percolation of four pore volumes (PV) (Fig. 2). Both ions showed the fastest breakthrough of all tracers suggesting only a weak interaction with the soil matrix; as in other studies, they can be considered as conservative tracers ${ }^{54,55}$. Nevertheless, in our experiment, this assumption was challenged by the observation in the youngest SIS (F.3): after the percolation of one PV, only $30 \% \mathrm{Br}^{-}$and $\mathrm{Cl}^{-}$broke through. Under the assumption that the transport of $\mathrm{Br}^{-}$and $\mathrm{Cl}^{-}$is only determined by convection, diffusion and dispersion, $50 \%$ of the solutes should have reached the outlet after one PV was exchanged ${ }^{56}$. The $20 \%$ deficit indicated that weak adsorption of $\mathrm{Br}^{-}$and $\mathrm{Cl}^{-}$occurred in $\mathrm{F} .3$ as was also observed by other researchers, e.g. ${ }^{57}$. In contrast, at W.10 and V.18 substantially more than $50 \% \mathrm{Br}^{-}$reached the outlet after one $\mathrm{PV}$, indicating fast transport of $\mathrm{Br}^{-}$in macropores. However, since the PV of the individual soil columns are only rough estimates, they are subject to uncertainty. Therefore, the deviation from $50 \%$ solute breakthrough at a PV equals one could also be partly explained by the uncertainties in the calculation of the PV.

With the exception of UR at V.18, BTCs of UR and SRB did not reach 100\% after four PV. Instead, their breakthrough maxima were $51 \pm 2 \%$ (F.3) and $79 \pm 1 \%$ (W.10) for UR; and $25 \pm 1 \%$ (F.3), $70 \pm 1 \%$ (W.10), and $90 \pm 2 \%$ (V.18) for SRB. Maxima of BTCs at F.3 and W.10 increased in the following order: $\mathrm{SRB}<\mathrm{UR}<\mathrm{Br}^{-} \approx \mathrm{Cl}^{-}$. At V.18, this order slightly differed ( $\mathrm{SRB}<\mathrm{UR} \approx \mathrm{Br}^{-} \approx \mathrm{Cl}^{-}$). These results indicated a stronger retention of the fluorescent tracers compared to $\mathrm{Br}^{-}$and $\mathrm{Cl}^{-}$most likely due to their higher adsorption affinity ${ }^{58}$. The higher retention of SRB compared to UR was in accordance with literature ${ }^{59,60}$ and linear sorption coeffients ( $\mathrm{K}_{d}$-values) for SRB that were about twice as high compared to UR (Table S1 and Figure S11) for all SIS. However, the high discrepancy between the retention of conservative tracers $\left(\mathrm{Br}^{-}, \mathrm{Cl}^{-}\right)$and UR at F.3 revealed that UR ought to be considered as a non-conservative tracer with respect to its sorption properties. This was described previously for UR application in soils with comparable OC content, texture and $\mathrm{pH}^{44,61,62}$.

We observed a faster breakthrough of all substances in W.10 and V.18 than in F.3 as indicated by higher slopes and higher maxima of BTCs (Fig. 2). After the percolation of one PV, 29\% (F.3), 73\% (W.10), and 93\% (V.18) of the $\mathrm{Br}^{-}$inflow concentrations were reached. Due to the small differences between the chemical soil properties of the SIS and the Kd values of UR and SRB (Table S1), we would have expected similar tracer BTCs. Yet, this was not the case; tracer retention decreased with age from the youngest to the oldest SIS (F. $3<<$ W.10 $<$ V.18). These differences could not be explained by chemical soil properties alone. When they would dominate solute transport, sorption, and thus solute retention should be highest at V.18 where OC content (1.9\%) and clay content $(8.8 \%)$ were highest and $\mathrm{pH}$ was lowest (7.1) (Table 1). From this we deduce that solute retention in W.10 and V.18 was controlled less by sorption than by preferential flow in macropores. Existing studies support this finding as they related fast transport of $\mathrm{SRB}^{42,43}$ and $\mathrm{UR}^{44}$ in undisturbed soil cores to the existence of preferential flow, too. Furthermore, our results imply the following: when preferential flow in macropores dominates water and solute transport, the differences in the BTCs of substances with different adsorption affinities decrease. This effect led to the largest differences between tracer BTCs in F.3, where matrix flow was dominant, and to the smallest differences between tracer BTCs in V.18, where preferential flow was dominant. In F.3, the matrix flow was high and solutes had a longer contact to a larger number of sorption sites thus intensifying sorption losses. In V.18, the opposite was true: the contact of the solutes to sorption sites was brief as they bypassed the soil matrix with the preferential flow. Additionally, the number of sorption sites may be lower in the preferential flow regions ${ }^{42}$. 


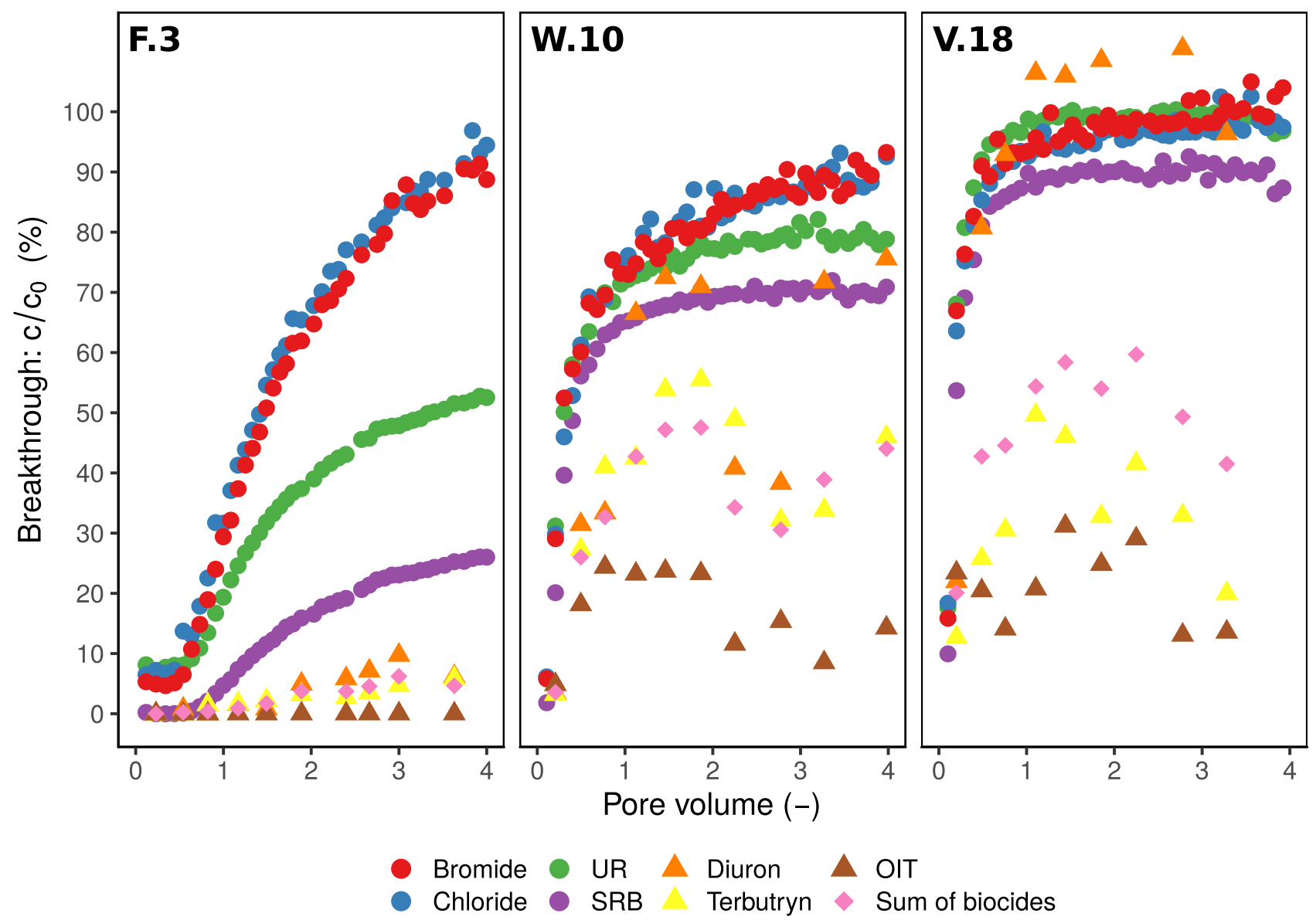

Figure 2. Breakthrough curves (BTCs) of the tracers bromide, chloride, UR, SRB and the biocides diuron, terbutryn, OIT and the sum of biocides (diuron+terbutryn+OIT; represented by diamonds). The normalized concentrations $\mathrm{c} / \mathrm{c}_{0}(\%)$ in the outflow from soil columns was plotted against the pore volume (-).
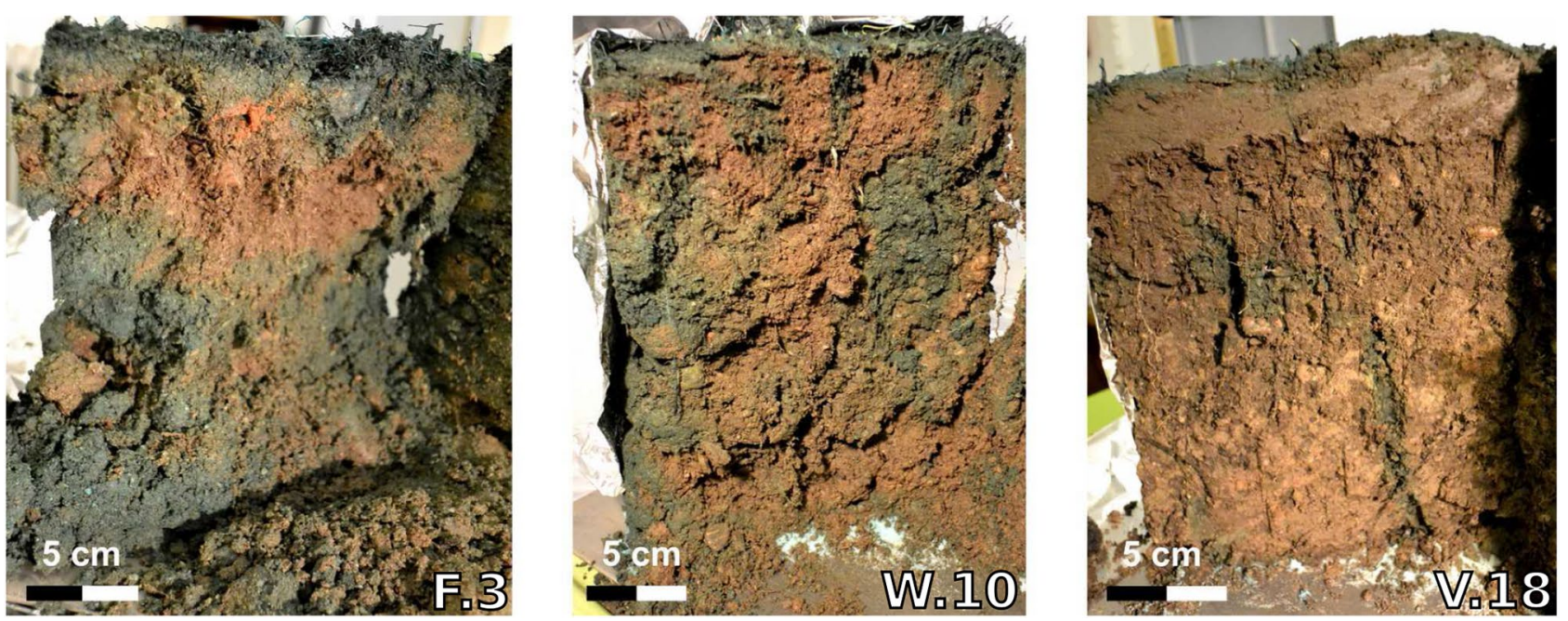

Figure 3. Brilliant blue stained soil columns (F.3, W.10 and V.18).

Furthermore, similar BTCs of conservative and non-conservative tracers with different adsorption affinities indicate strong transport in macropores by preferential flow ${ }^{63-65}$.

Brilliant blue staining. Roughly $65 \%$ of F.3, $38 \%$ of W.10 and $8 \%$ of V.18 (Figure S10) were stained. Along the cut profile large blue patches were visible for F.3 while only single blue fingers were observable for V.18 (Fig. 3). These macropores, especially in V.18, were most probably caused by earthworms ${ }^{45,66}$. In fact, approximately ten 


\begin{tabular}{|c|c|c|c|c|c|}
\hline & $\mathbf{U R}^{a}$ & SRB $^{a}$ & Diuron & OIT & Terbutryn \\
\hline Structure & & 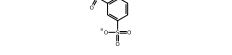 & & & \\
\hline Formula & $\mathrm{C}_{20} \mathrm{H}_{10} \mathrm{O}_{5} \mathrm{Na}_{2}$ & $\mathrm{C}_{27} \mathrm{H}_{29} \mathrm{~N}_{2} \mathrm{NaO}_{7} \mathrm{~S}_{2}$ & $\mathrm{C}_{9} \mathrm{H}_{10} \mathrm{Cl}_{2} \mathrm{~N}_{2} \mathrm{O}$ & $\mathrm{C}_{11} \mathrm{H}_{19} \mathrm{NOS}$ & $\mathrm{C}_{10} \mathrm{H}_{19} \mathrm{~N}_{5} \mathrm{~S}$ \\
\hline $\mathrm{M}_{w}\left(\mathrm{~g} \mathrm{~mol}^{-1}\right)$ & 332 & 580 & 234 & 214 & 241 \\
\hline $\begin{array}{l}\text { Ex./Em. (nm) } \\
\text { solubility at }\end{array}$ & $491 / 516^{e}$ & $560 / 585^{e}$ & - & - & \\
\hline $20^{\circ} \mathrm{C}\left(\mathrm{gL}^{-1}\right)$ & $300^{e}$ & $10\left(10^{\circ} \mathrm{C}\right)^{e}$ & $0.035^{f}$ & $0.500^{f}$ & $0.025^{f}$ \\
\hline $\log \left(\mathrm{K}_{O W}\right)$ & $3.35^{b} /-0.67^{c}$ & $1.3^{d}$ & $2.87^{f}$ & $2.45^{f}-3.77^{g}$ & $3.66^{f}$ \\
\hline $\begin{array}{l}\mathrm{pK}_{a}(-) \\
\text { half-life }\end{array}$ & $1.95 / 5.05 / 7.00^{h}$ & $<1.5^{i}$ & & & \\
\hline in soil (d) & - & - & $>2500^{j}$ & $9.3^{j}$ & $231^{j}$ \\
\hline
\end{tabular}

Table 3. Characterisation of fluorescent tracers and biocides. ${ }^{a}$ Color Index (Name:Number): UR (Acid Yellow $73: 45350)^{58}$; SRB (Acid Rd $\left.52: 45100\right)^{58} ;{ }^{b} \log \left(\mathrm{K}_{O W}\right)$ for the twofold protonated (neutral) species (dominant species between $\mathrm{pH} 1.95$ and 5.05), Calculated with Estimation Programs Interface Suite for Microsoft Windows, $v 4.11^{99} ;{ }^{c} \log \left(\mathrm{K}_{O W}\right)$ for the disodium salt (twofold negative charged) species (dominant species above $\mathrm{pH}$ 7.00), Calculated with Estimation Programs Interface Suite for Microsoft Windows, v $4.11^{99} ;{ }^{d} \log \left(\mathrm{K}_{O W}\right)$ at pH 7.15 ${ }^{100}$; ${ }^{e}$ Source: $:{ }^{58} ;{ }^{f}$ Source: ${ }^{94} ;{ }^{g}$ Source: ${ }^{101} ;{ }^{h}$ Source: ${ }^{102} ;{ }^{i}$ Source: ${ }^{103} ;{ }^{j}$ Source: ${ }^{29}$.

individuals were observed on the laboratory columns after saturation from bottom to top. Earthworm holes were visible on the soil surface as well as on horizontal and vertical cuts through the soil column (approximately 2-3 mm, Figure S9). At W.10 several ants were observed that also could cause macropores ${ }^{67,68}$. In contrast, no macrofauna was visible at F.3. Overall, brilliant blue patterns supported the assumption of an increasing fraction of preferential flow in the older SIS W.10 and V.18.

Brilliant blue staining also revealed partial water flow on the soil column sidewall ${ }^{69}$ that bypassed a part of the soil column F.3 and entered the soil again further down (Fig. 3). This partial sidewall flow could potentially explain the fast initial $\mathrm{Br}^{-}, \mathrm{Cl}^{-}$and UR breakthrough in F.3 where 5-10\% of the tracers was measured in the first sample taken after $30 \mathrm{~min}$ (Fig. 2). However, this effect was limited since concentrations remained only initially constant and increased again after approximately 0.5 PV. Interestingly, this effect could not be observed for the stronger adsorbing SRB. Possibly, SRB was initially retained and therefore could not be measured in the first percolates. Similar transport characteristics of UR and SRB in the beginning of the experiment were observed e.g. in the study conducted by ${ }^{70}$.

Biocide breakthrough. At all sites, the biocide breakthrough increased in the following order: OIT $<$ terbutryn $<$ diuron. This order followed the polarity of the substances as indicated by the $\mathrm{K}_{O W}$-values (Table 3 ) which can be interpreted as a rough estimate for the sorption affinity of non-polar substances to organic matter ${ }^{71,72}$. Furthermore, except for diuron at W.10 and V.18, biocides were more strongly retained than the tracers in all SIS. This observation may be explained as follows: the walls of macropores caused by earthworms may be enriched with soil organic matter ${ }^{73}$. These macropores may provide hydrophobic sorption sites (organic matter) for non-polar substances such as biocides and less for the polar tracers.

Analogous to UR and SRB, the retention of biocides was highest in F.3 (Fig. 2), followed by W.10 and V.18 and was negatively related to the OC content of all SIS (Table 1). Similar to the tracers, the large differences in BTCs of biocides between the SIS cannot be explained by chemical soil properties but rather by soil structure. In F.3, biocides had more intense contact with the soil matrix than in W.10 and V.18 due to a higher fraction of matrix flow. As a result, biocide retention was highest in F.3 despite the lowest OC content. Thus, the influence of biocide properties on their retention was strongly reduced by preferential flow in macropores ${ }^{74,75}$.

Although biocide degradation is unlikely due to the short duration of the experiment (approximately 13-28 h) and due to immediate cooling and freezing of the samples after sampling, these processes could not be completely ruled out. However, if a small amount of biocide degradation occurred, then concentrations would have been reduced by the same amount in all samples. The differences in biocide concentrations between the individual soil columns should not have been affected.

The rapid leaching of organic pollutants through macropores, has also been observed in several studies for pesticides in agricultural soils ${ }^{38,39}$. More biocide breakthrough in W.10 and V.18, especially that of diuron in V.18 is in line with findings of ${ }^{76}$, who reported leaching of diuron due to complexation of diuron with dissolved organic matter (DOM). This indicates that DOM molecules have a dual role on pollutant transport in soils: they compete for adsorption of the organic pollutants and enhance their mobility by complexation. But their leaching is enhanced by preferential transport in macropores following intense rainfall ${ }^{77}$ or in strongly structured soils with connection to shallow groundwater ${ }^{78}$.

Important factors of fast solute breakthrough in urban SIS and implications for storm water treatment. Despite similar chemical soil properties between the SIS, W.10 and V.18 showed a much faster tracer and biocide breakthrough compared to F.3. Brilliant blue patterns and saturated hydraulic conductivities indicated prevailing preferential flow conditions in macropores in SIS W.10 and V.18 that lead to fast solute 
breakthrough. Macropores can be caused by biological activity ${ }^{41,79}$, which is supported by the observation of the highest activity of macrofauna (earthworms and ants) in the older SIS W.10 and V.18. Therefore, in our experiment the age of SIS is closely related to macrofauna activity. This observation is in agreement with results from ${ }^{80}$ who found an increasing earthworm population density with increasing age of different urban landscapes. Similar observations were made by ${ }^{81}$ in technosols but they concluded that the existence of an initial addition of topsoil is required, which was the case in all SIS of our study.

Beside the age of a soil, the abundance of earthworms is also controlled by bulk density and soil depth ${ }^{82}$. In SIS V.18 bulk density was lowest and soil depth highest, both factors favoring high earthworm abundance. Thus, different relevance of preferential flow in the different SIS may also be due to differences in the construction of the SIS. If a SIS is built with a less thick topsoil layer or a high bulk density, or if other macrofauna-inhibiting factors play a role, the development of the macrofauna may be restricted, making the development of preferential flow paths in aging SIS less likely. Furthermore, climate can influence the population dynamics of earthworms ${ }^{83,84}$. Therefore, we conclude that factors supporting higher activity of macrofauna (e.g. earthworms and ants) in SIS may also lead to faster solute breakthrough.

Additional influence on macropore formation can be exerted by the vegetation of the swales, directly by plants with thicker or deeper roots colonizing as development of the swales progresses, or indirectly by influencing the diversity of invertebrates ${ }^{85}$. Due to necessary time for colonization and establishment of species also the age of swales may be linked to the biodiversity. In addition to vegetation and soil structure, the shape of the swales could also have an influence on diversity of invertebrate and thus on macropore formation. Reference ${ }^{85}$ supposed that biodiversity may be higher in round systems than in linear ones. However, we observed rather the opposite, suggesting that age played a greater role for macrofauna diversity and macropore formation than swale shape in our experiments.

Our experiment has shown that SIS can retain biocides by adsorption when the substances have sufficient contact with the soil matrix. Inversely, our study also suggests a decrease in biocide retention capacity in urban SIS due to preferential flow pathways caused by an increasing biological activity and changing soil properties already after 10-18 years of operation. However, biological activity in SIS is also desirable due to several benefits. Higher biodiversity of vegetation and soil fauna may enhance degradation of several organic pollutants and higher infiltration rates, e.g. due to a higher number of macropores, may guaranty fast water infiltration even after long-term operation. Overall, we recommend regular monitoring of the pollutant retention capacity of SIS to detect its reduction in time, which could be done, for example, by tracer experiments.

One approach to address this problem is to treat storm water with special adsorbent materials ${ }^{86,87}$ before it enters the swales, or integrate additional adsorbent layers in the swales. However, these options are complex and expensive and, furthermore, a large portion of urban runoff often infiltrates diffusely and does not reach the swales at all. Therefore, a more sustainable approach, is to avoid biocide pollution at the source ${ }^{88,89}$, which would allow a targeted urban water management by SIS that preserves urban groundwater quality.

\section{Methods}

Study sites and soil characterization. We selected three SIS of different age (F.3, W.10 and V.18) in the city of Freiburg, south-west Germany (Figure S1). F.3 (3 years old) was a nearly rectangular shaped swale (approx. $600 \mathrm{~m}^{2}$ ) that drained a commercial area, W.10 (10 years old) a rectangular multilevel swale system (approx. $700 \mathrm{~m}^{2}$ ), and V.18 (18 years old) an elongated swale-trench system (approx. $3000 \mathrm{~m}^{2}$ ), both drained a residential area. F. 3 consisted of a $25-30 \mathrm{~cm}$ topsoil layer over the natural soil layer. Beneath a $30-50 \mathrm{~cm}$ topsoil layer of W.10 and V.18 there was a $20 \mathrm{~cm}$ sand layer followed by a gravel-filled drain trench to collect and drain the seepage water. To ensure comparability despite different SIS geometry, all samples were taken in the intermediate vicinity of the inflow and from similar depths $(20-25 \mathrm{~cm})$. Moreover, the inflow area is particularly interesting because it represents the entry point of pollutants in the SIS. The vegetation of the swales consisted mainly of grass as well as clover (Trifolium), dandelion (Taraxacum) and ribwort (Plantago).

From each SIS, four fixed volume soil cores (diameter: $8 \mathrm{~cm}$, length: $15 \mathrm{~cm}$ ) were taken with a root auger in a $2 \times 2 \mathrm{~m}$ square at two depths $(0-15 \mathrm{~cm}$ and $15-30 \mathrm{~cm})$. This was performed in two steps (Figure S2): after taking the upper soil core $(0-15 \mathrm{~cm})$, the deeper one was taken from the same bore hole $(15-30 \mathrm{~cm})$.

Using a knife, each soil core was cut into $5 \mathrm{~cm}$ wide pieces resulting in five (F.3, W.10) and six (V.18) depthrelated soil samples $(0-5 \mathrm{~cm}, 5-10 \mathrm{~cm}, 10-15 \mathrm{~cm}, 15-20 \mathrm{~cm}, 20-25 \mathrm{~cm}, 25-30 \mathrm{~cm} ; \mathrm{n}=4)$. Soil samples were air-dried and weighed to calculate bulk density. Subsequently, the soil samples passed through a $2 \mathrm{~mm}$ sieve and stones (inorganic particles $>2 \mathrm{~mm}$ ) and roots were weighed separately. We determined the residual gravimetric water content as the difference between the weight of an air-dried soil sample before and after $24 \mathrm{~h}$ of drying at $105^{\circ} \mathrm{C}$. The $\mathrm{pH}$ was measured from over-night, $25 \mathrm{ml} 0.01 \mathrm{M} \mathrm{CaCl}_{2}$ supsensions of $10 \mathrm{~g}$ soil at room temperature $\left(23^{\circ} \mathrm{C} \pm 2^{\circ} \mathrm{C}\right.$ ) with a pH meter (Deutsche METROHM GmbH \& Co KG, Filderstadt, Germany). The content of sand, silt and clay (inorganic particles $<2 \mathrm{~mm}$; fine soil) were determined by sieving, sedimentation and the pipette $\operatorname{method}^{90}$. The OC content was determined by a CNS-analyzer (vario EL cube, Elementar Analysensysteme $\mathrm{GmbH}$, Germany). Due to the possible carbonate content $(\mathrm{pH}>7.0)$, the $\mathrm{OC}$ content of the soil samples was determined as the difference of total carbon before and after heating at $550^{\circ} \mathrm{C}$. At this temperature $\mathrm{OC}$ had been transformed to $\mathrm{CO}_{2}{ }^{91}$. Additionally, sorption isotherms for UR and SRB were produced according to OECD guideline $106^{92}$ described in $^{62}$ and linear sorption coeffients ( $\mathrm{K}_{d}$-values) were calculated.

Percolation experiment. In every SIS, one intact soil column was collected using a stainless steel cylinder (diameter: $20 \mathrm{~cm}$, length: $30 \mathrm{~cm}$ ) that was knocked into the soil. The cylinder was excavated and the embedded soil column was pushed into a second steel cylinder (Figure S3). The bottom of the soil column was straightened with a knife and approx. $1-2 \mathrm{~cm}$ sand was added to ensure connection to a $0.45 \mu \mathrm{m}$ nylon membrane. The height 
of soil column F.3 was lower $(21 \mathrm{~cm})$ than of W.10 and V.18 $(25 \mathrm{~cm})$ because the soil layer of F.3 was shallower. During sampling, the vegetation was left on the soil column as far as possible. Where it was too long, it was superficially shortened. Plants were not removed so as not to disturb the soil structure.

The top of the soil column was connected to two storage vessels (Figures S5, S6). The first storage vessel was connected via a tube with a small liquid layer on the top of the soil (approximately $2 \mathrm{~cm}$ ). The second storage vessel was connected to the first one with two tubes that kept the water level between the storage vessels and the soil column constant. At the bottom of the soil column, the solution was placed under tension with a $45 \mathrm{~cm}$ water head to quicken flow rates and thus reduce anaerobic conditions in the soil column. The bottom of the column was enclosed with a $0.45 \mu \mathrm{m}$ nylon membrane. The percolate was collected in $1 \mathrm{~L}$-glass bottles that were placed on weighing devices (Figure S5) to calculate the flow rate. To avoid photodegradation, all vessels, tubes and bottles were wrapped with aluminum foil. The soil columns were saturated with deionized water from bottom to top at $7 \mathrm{~cm} \mathrm{~d}^{-1}$. Thereafter, deionized water was percolated to reach constant flow conditions and to decrease the DOC load of the percolate. Pre-tests with $\mathrm{Br}^{-}(\mathrm{NaBr}$, Carl Roth $\mathrm{GmbH} \& \mathrm{Co} \mathrm{KG}$, Karlsruhe, Germany) were conducted to set up a sampling protocol for each soil column. Before starting the main experiment, $\mathrm{Br}^{-}$was washed out by deionized water.

The main percolation experiment started with a $1.5 \mathrm{~h}$ flushing of the soil columns with deionized water. Subsequently, all water in the storage vessels and on the soil surface was replaced by a tracer/biocide solution. For each soil column, $15 \mathrm{~L}$ of initial solution consisting of deionized water, tracers and biocides were prepared. Target tracer concentrations were $50 \mathrm{mg} \mathrm{L}^{-1} \mathrm{Br}^{-}, 25 \mathrm{mg} \mathrm{L}^{-1} \mathrm{Cl}^{-}\left(\mathrm{CaCl}_{2}\right.$, VWR International GmbH, Darmstadt, Germany), $10 \mathrm{mg} \mathrm{L}^{-1} \mathrm{UR}$ (Simon \& Werner GmbH, Flörsheim, Germany), $400 \mathrm{mg} \mathrm{L}^{-1} \mathrm{SRB}$ (Chroma GmbH \& Co KG, Münster, Germany). Target biocide concentrations are based on commonly measured concentrations in facade runoff ${ }^{93}$ and were $50 \mathrm{mg} \mathrm{L}^{-1}$ each of diuron, terbutryn (NEOCHEMA GmbH, Bodenheim, Germany) and OIT (Sigma-Aldrich Chemie GmbH, Taufkirchen, Germany). The tracer stock solutions were prepared with deionized water and solid substances, while the biocides were already dissolved in acetonitrile by the manufacturer. UR and SRB solutions were stored in amber glass bottles and wrapped with aluminum foil to prevent photolytic decay.

The measured initial concentrations only slightly deviated from the intended concentrations (Table S5). The experiment lasted for $28 \mathrm{~h}$ (F.3) and $12.7 \mathrm{~h}$ (W.10, V.18) depending on the flow velocity. We excluded biodegradation of biocides since their half-times in soils are much higher than the duration of the experiment ${ }^{29}$. Furthermore, terbutryn, diuron and OIT are assumed to be stable to aqueous hydrolysis ${ }^{28,94}$. In the beginning of the experiment, samples of the percolate were taken every $15 \mathrm{~min}$, later every 20, 30, 45 or $60 \mathrm{~min}$. An aliquot of the collected percolate was filled into $100 \mathrm{~mL}$ amber glass bottles for UR, SRB and biocide measurements, and $100 \mathrm{~mL}$ polyethylene bottles for $\mathrm{Br}^{-}, \mathrm{Cl}^{-}$and $\mathrm{pH}$ measurements. Samples were stored at approximately $6^{\circ} \mathrm{C}$ for measurement for a maximum of ten days and frozen for longer storage. No changes in concentrations were observed in preliminary laboratory tests measuring biocide concentrations before and after storage (freezing of samples for multiple weeks).

The estimated total pore volume $\mathrm{PV}_{\text {tot,est }}(\mathrm{L})$ of each soil column (Table 2) was calculated by the following:

$$
P V_{\text {tot }, e s t}(L)=\text { porosity }(-) \cdot\left(1-\left(\frac{\text { stone content }(\%)}{100 \%}\right)\right) \cdot \text { total volumn of the soil column }(\mathrm{L}) .
$$

The porosity (-) was estimated according to ${ }^{50}$, who provide average porosities for soils in dependence of their texture and OM content. The estimated water volume that flowed through the column at time $\left.\mathrm{PV}_{t} \mathrm{LL}^{-1}\right)$ was calculated by dividing the outflow $(\mathrm{L})$ at a certain time step by $\mathrm{PV}_{\text {tot,est }}$. $\mathrm{PV}_{t}$ was used to normalize the percolated amount of water and make solute transport comparable. Maxima of BTCs of the solutes were estimated by calculating the mean breakthrough (\%) between PVs of three and four. The saturated hydraulic conductivity $\mathrm{K}_{s}$ $\left(\mathrm{cm} \mathrm{h} \mathrm{h}^{-1}\right)$ was calculated according to Darcy's law:

$$
q=K_{s} \cdot \frac{\Delta H}{L} .
$$

where $\mathrm{q}\left(\mathrm{cm} \mathrm{h}^{-1}\right)$ is the water flow through the soil column, $\Delta H(\mathrm{~cm})$ is the hydraulic head difference between upper and lower boundary of the soil column, and L $(\mathrm{cm})$ is the length of the column. Data analysis was performed with R statistics (version 3.3.4) ${ }^{95}$.

Brilliant blue staining. To identify preferential flow in soils of SIS we used brilliant blue staining as was done before e.g. by ${ }^{42,}{ }^{96}$. In each soil column about $3.5 \mathrm{~L}$ (approximately one PV) brilliant blue FCF (Waldeck $\mathrm{GmbH} \& \mathrm{Co} \mathrm{KG}$, Germany) solution $\left(c=2 \mathrm{~g} \mathrm{~L}^{-1}\right)$ was applied. Due to different flow velocities, it took $23 \mathrm{~h}$ (F.3), $8.2 \mathrm{~h}$ (W.10) and $5.2 \mathrm{~h}$ (V.18) until the brilliant blue solution infiltrated. Subsequently, we removed the soil column from the steel cylinders, cut them in half using a knife and photographed them (Canon 450D) to make flow pathways visible. Pictures were processed by Gimp 2.10 (The GIMP team, www.gimp.org) and ImageJ-win 64 (Fiji Is Just ImageJ, fiji.sc) ${ }^{97}$ (see Note S1). The correlation between the brilliant blue stained area of the soil columns and the breakthrough maxima was tested with Pearson correlation coefficients.

Measurement of salt and fluorescent tracers. UR and SRB (Table 3) fluorescence was measured at $488 \mathrm{~nm}$ (UR) and $560 \mathrm{~nm}(\mathrm{SRB})$ in a synchronous scan method (wavelength range: $\lambda=250-650 \mathrm{~nm}$, $\Delta \lambda=25 \mathrm{~nm}$ ) using the luminescence spectrometer LS-50B (Perkin Elmer, MA, USA). Due to sensitivity of tracer fluorescence to $\mathrm{pH}^{98}$, it was buffered before measurement at 9-10 using one drop of 1.5 M EDTA to ensure $100 \%$ fluorescence intensity for both tracers. To ensure a linear calibration range, the calibration solutions were 
prepared in the ranges $0.25-5 \mu \mathrm{gL}^{-1}$ (UR) and 5-90 $\mu \mathrm{gL}^{-1}$ (SRB). The calibration of UR and SRB was performed separately for each SIS (extracting agent: $0.01 \mathrm{M} \mathrm{CaCl}_{2}$ solution, soil:solution-ratio: 1:5). Samples for the measurement of UR and SRB were diluted 1:10 to reduce DOC background fluorescence and to maintain the calibration range. $\mathrm{Br}^{-}$and $\mathrm{Cl}^{-}$were measured by ion chromatography (790 Personal IC, Deutsche METROHM GmbH \& Co KG, Filderstadt, Germany).

Measurement of biocides. Analysis of terbutryn, diuron and OIT was already described in detail in ${ }^{28,104}$. For measurement of biocides, $3 \mathrm{~mL}$ of the percolates were evaporated to dryness with a Büchi Syncore Polyvap (BÜCHI Labortechnik GmbH, Essen, Germany) and taken up in $0.3 \mathrm{~mL}$ acetonitrile (enrichment factor of 10). $90 \mu \mathrm{L}$ of the percolate sample containing biocides were spiked with $10 \mu \mathrm{L}$ of terbutryn-D5 as an internal standard. Measurements of percolate samples were conducted with a Triple Quadrupole mass spectrometer (Agilent Technologies, 1200 Infinity LC-System and 6430 Triple Quad, Waldbronn, Germany). Therefore, a NUCLEODUR RP-C18 column (125/2 100-3 L C18 ec; MACHEREY-NAGEL GmbH \& Co KG, Düren, Germany) was used as stationary phase, whereas $0.01 \%$ formic acid (A) and acetonitrile (B) were used as mobile phases with a flow of $0.4 \mathrm{~mL} \mathrm{~min}^{-1}$ and the following concentration gradient: $10 \% \mathrm{~B}(0-1 \mathrm{~min}), 10-50 \% \mathrm{~B}(1-11 \mathrm{~min}), 50-85 \%$ B (11-18 min), 85-90\% B (18-21 min), 90\% B (21-24 min), 90-10\% B (24-26 min), 10\% B (26-30 min). Oven temperature was $\mathrm{T}=30^{\circ} \mathrm{C}$ and injection volume $5 \mu \mathrm{L}$. Mass spectrometric settings are listed in Table S2. The linearity between peak area and concentration of substances were obtained in a range of $0-5 \mu \mathrm{g} \mathrm{L}^{-1}$. Hence, limits of detection (LOD) and quantitation (LOQ) were calculated with DINTEST (2003) according to DIN 32645 and amounted to 1 and $2.65 \mu \mathrm{g} \mathrm{L}^{-1}$ (diuron), 0.76 and $2.94 \mu \mathrm{g} \mathrm{L}^{-1}$ (terbutryn), 0.86 and $2.99 \mu \mathrm{g} \mathrm{L}^{-1}$ (OIT), respectively.

\section{Data availability}

All data generated or analyzed during this study are included in this published article (and its Supplementary Information files).

Received: 15 September 2020; Accepted: 15 March 2021

Published online: 31 March 2021

\section{References}

1. Barbosa, A. E., Fernandes, J. N. \& David, L. M. Key issues for sustainable urban stormwater management. Water Res. 46, 6787-6798. https://doi.org/10.1016/j.watres.2012.05.029 (2012).

2. Fletcher, T. D., Andrieu, H. \& Hamel, P. Understanding, management and modelling of urban hydrology and its consequences for receiving waters: A state of the art. Adv. Water Resour. 51, 261-279. https://doi.org/10.1016/j.advwatres.2012.09.001 (2013).

3. Eckart, K., McPhee, Z. \& Bolisetti, T. Performance and implementation of low impact development-a review. Sci. Total Environ. 607-608, 413-432. https://doi.org/10.1016/j.scitotenv.2017.06.254 (2017)

4. Li, C. et al. Mechanisms and applications of green infrastructure practices for stormwater control: A review. J. Hydrol. 568, 626-637. https://doi.org/10.1016/j.jhydrol.2018.10.074 (2019).

5. Bundesministerium der Justiz und für Verbraucherschutz. Gesetz zur ordnung des wasserhaushalts (wasserhaushaltsgesetz-whg) (2009).

6. Göbel, P. et al. Near-natural stormwater management and its effects on the water budget and groundwater surface in urban areas taking account of the hydrogeological conditions. J. Hydrol. 299, 267-283. https://doi.org/10.1016/j.jhydrol.2004.08.013 (2004).

7. Shuster, W. D., Gehring, R. \& Gerken, J. Prospects for enhanced groundwater recharge via infiltration of urban storm water runoff: A case study. J. Soil Water Conserv. (J. Soil Water Conserv.) 62, 129-137 (2007).

8. Lucke, T. \& Nichols, P. W. B. The pollution removal and stormwater reduction performance of street-side bioretention basins after ten years in operation. Sci. Total Environ. 536, 784-792. https://doi.org/10.1016/j.scitotenv.2015.07.142 (2015).

9. Endreny, T. \& Collins, V. Implications of bioretention basin spatial arrangements on stormwater recharge and groundwater mounding. Ecol. Eng. 35, 670-677. https://doi.org/10.1016/j.ecoleng.2008.10.017 (2009).

10. Dillon, P. et al. Managed aquifer recharge: Rediscovering nature as a leading edge technology. Water Sci. Technol. 62, 2338-2345. https://doi.org/10.2166/wst.2010.444 (2010).

11. Schirmer, M., Leschik, S. \& Musolff, A. Current research in urban hydrogeology—a review. Adv. Water Resour. 51, $280-291$. https://doi.org/10.1016/j.advwatres.2012.06.015 (2013).

12. Boller, M. Towards sustainable urban stormwater management. Water Sci. Technol. Water Supply 4, 55-65 (2004).

13. Davis, A. P., Shokouhian, M., Sharma, H. \& Minami, C. Water quality improvement through bioretention media: Nitrogen and phosphorus removal. Water Environ. Res. Res. Publ. Water Environ. Feder. 78, 284-293. https://doi.org/10.2175/106143005X 94376 (2006).

14. Mikkelsen, P. S. et al. Pollution of soil and groundwater from infiltration of highly contaminated stormwater-a case study. Water Sci. Technol.https://doi.org/10.1016/S0273-1223(97)00578-7 (1997).

15. Wong, C. S. C., Li, X. \& Thornton, I. Urban environmental geochemistry of trace metals. Environ. Pollut. 142, 1-16. https://doi. org/10.1016/j.envpol.2005.09.004 (2006).

16. Göbel, P., Dierkes, C. \& Coldewey, W. G. Storm water runoff concentration matrix for urban areas. J. Contam. Hydrol. 91, 26-42. https://doi.org/10.1016/j.jconhyd.2006.08.008 (2007).

17. LeFevre, G. H. et al. Review of dissolved pollutants in urban storm water and their removal and fate in bioretention cells. J. Environ. Eng. 141, 04014050. https://doi.org/10.1061/(ASCE)EE.1943-7870.0000876 (2015).

18. Bucheli, T. D., Müller, S. R., Heberle, S. \& Schwarzenbach, R. P. Occurrence and behavior of pesticides in rainwater, roof runoff, and artificial stormwater infiltration. Environ. Sci. Technol. 32, 3457-3464. https://doi.org/10.1021/es980317n (1998).

19. Zgheib, S., Moilleron, R. \& Chebbo, G. Priority pollutants in urban stormwater: Part 1-case of separate storm sewers. Water Res. 46, 6683-6692. https://doi.org/10.1016/j.watres.2011.12.012 (2012).

20. Ensminger, M. P., Budd, R., Kelley, K. C. \& Goh, K. S. Pesticide occurrence and aquatic benchmark exceedances in urban surface waters and sediments in three urban areas of california, usa, 2008-2011. Environ. Monit. Assess. 185, 3697-3710. https://doi. org/10.1007/s10661-012-2821-8 (2013).

21. Paulus, W. (ed.) Directory of Microbicides for the Protection of Materials (Springer, 2005).

22. Burkhardt, M. et al. Leaching of additives from construction materials to urban storm water runoff. Water Sci. Technol. 63, 1974. https://doi.org/10.2166/wst.2011.128 (2011). 
23. Burkhardt, M. et al. Leaching of biocides from façades under natural weather conditions. Environ. Sci. Technol. 46, 5497-5503. https://doi.org/10.1021/es2040009 (2012).

24. Wittmer, I. K., Scheidegger, R., Stamm, C., Gujer, W. \& Bader, H.-P. Modelling biocide leaching from facades. Water Res. 45, 3453-3460. https://doi.org/10.1016/j.watres.2011.04.003 (2011).

25. Bollmann, U. E. et al. Leaching of terbutryn and its photodegradation products from artificial walls under natural weather conditions. Environ. Sci. Technol. 50, 4289-4295. https://doi.org/10.1021/acs.est.5b05825 (2016).

26. Bollmann, U. E., Vollertsen, J., Carmeliet, J. \& Bester, K. Dynamics of biocide emissions from buildings in a suburban stormwater catchment-concentrations, mass loads and emission processes. Water Res. 56, 66-76. https://doi.org/10.1016/j.watres.2014.02. 033 (2014).

27. Schoknecht, U., Mathies, H. \& Wegner, R. Biocide leaching during field experiments on treated articles. Environ. Sci. Eur. 28, 2850. https://doi.org/10.1186/s12302-016-0074-9 (2016).

28. Hensen, B. et al. Entry of biocides and their transformation products into groundwater via urban stormwater infiltration systems. Water Res. 144, 413-423. https://doi.org/10.1016/j.watres.2018.07.046 (2018).

29. Bollmann, U. E. et al. Biocide runoff from building facades: Degradation kinetics in soil. Environ. Sci. Technol. 51, 3694-3702. https://doi.org/10.1021/acs.est.6b05512 (2017).

30. U.S. Environmental Protection Agency. Low impact development (lid): A literature review (2000).

31. German Association for Water, Wastewater and Waste. Planning, construction and operation of facilities for the percolation of precipitation water: Standard DWA-A 138E. German DWA rules and standards (DWA, Hennef, 2006), April 2005, engl. version edn.

32. Tedoldi, D. et al. Spatial distribution of heavy metals in the surface soil of source-control stormwater infiltration devices - intersite comparison. Sci. Total Environ. 579, 881-892. https://doi.org/10.1016/j.scitotenv.2016.10.226 (2017).

33. Kluge, B. et al. Metal accumulation and hydraulic performance of bioretention systems after long-term operation. J. Soils Sedim. 55, 193. https://doi.org/10.1007/s11368-016-1533-z (2016).

34. Gavrilescu, M. Fate of pesticides in the environment and its bioremediation. Eng. Life Sci. 5, 497-526. https://doi.org/10.1002/ elsc.200520098 (2005).

35. Bergman, M. et al. Evaluation of two stormwater infiltration trenches in central copenhagen after 15 years of operation. Water Sci. Technol. 63, 2279-2286. https://doi.org/10.2166/wst.2011.158 (2011).

36. Ruiner, H., Leonhardt, G., Marsalek, J., Perttu, A.-M. \& Viklander, M. The effects of initial soil moisture conditions on swale flow hydrographs. Hydrol. Process. 32, 644-654. https://doi.org/10.1002/hyp.11446 (2018).

37. Larsbo, M., Stenström, J., Etana, A., Börjesson, E. \& Jarvis, N. J. Herbicide sorption, degradation, and leaching in three Swedish soils under long-term conventional and reduced tillage. Soil Tillage Res. 105, 200-208. https://doi.org/10.1016/j.still.2009.08. 003 (2009).

38. Zehe, E. \& Flühler, H. Preferential transport of isoproturon at a plot scale and a field scale tile-drained site. J. Hydrol. 247, 100-115. https://doi.org/10.1016/S0022-1694(01)00370-5 (2001).

39. Dousset, S., Thevenot, M., Pot, V., Simunek, J. \& Andreux, F. Evaluating equilibrium and non-equilibrium transport of bromide and isoproturon in disturbed and undisturbed soil columns. J. Contam. Hydrol. 94, 261-276. https://doi.org/10.1016/j.jconhyd. 2007.07.002 (2007).

40. Burkhardt, M. et al. Biozide in gebäudefassaden-ökotoxikologische effekte, auswaschung und belastungsabschätzung für gewässer. Umweltwiss. Schadst. Forsch. 21, 36-47. https://doi.org/10.1007/s12302-008-0033-1 (2009).

41. Weiler, M. \& Naef, F. An experimental tracer study of the role of macropores in infiltration in grassland soils. Hydrol. Process. 17, 477-493. https://doi.org/10.1002/hyp.1136 (2003).

42. Vanderborght, J., Gähwiller, P. \& Flühler, H. Identification of transport processes in soil cores using fluorescent tracers. Soil Sci. Soc. Am. J. 66, 774-787. https://doi.org/10.2136/sssaj2002.0774 (2002).

43. Albrecht, A. et al. Behavior of a surface applied radionuclide and a dye tracer in structured and repacked soil monoliths. J. Environ. Radioact. 68, 47-64. https://doi.org/10.1016/S0265-931X(03)00029-8 (2003).

44. Torrentó, C. et al. Adsorbing vs. nonadsorbing tracers for assessing pesticide transport in arable soils. Vadose Zone J. 17, 0. https://doi.org/10.2136/vzj2017.01.0033 (2018).

45. Blume, H.-P. et al. Scheffer/Schachtschabel Soil Science (Springer, 2016).

46. Li, H. \& Davis, A. P. Urban particle capture in bioretention media. ii: Theory and model development. J. Environ. Eng. 134, 419-432. https://doi.org/10.1061/(ASCE)0733-9372(2008)134:6(419) (2008).

47. Totsche, K. U., Danzer, J. \& Kögel-Knabner, I. Dissolved organic matter-enhanced retention of polycyclic aromatic hydrocarbons in soil miscible displacement experiments. J. Environ. Qual. 26, 1090-1100. https://doi.org/10.2134/jeq1997.004724250026000 40021x (1997).

48. Meyer-Windel, S., Lennartz, B. \& Widmoser, P. Bromide and herbicide transport under steady-state and transient flow conditions. Eur. J. Soil Sci. 50, 23-33. https://doi.org/10.1046/j.1365-2389.1999.00210.x (2003).

49. Jaesche, P., Totsche, K. U. \& Kögel-Knabner, I. Transport and anaerobic biodegradation of propylene glycol in gravel-rich soil materials. J. Contam. Hydrol. 85, 271-286. https://doi.org/10.1016/j.jconhyd.2006.02.003 (2006).

50. Eckelmann, W. et al.Bodenkundliche Kartieranleitung. KA 5 (Schweizerbart Science Publishers, Stuttgart, Germany, 2006) 5. verbess. und erw. auflage edn.

51. Torkzaban, S. et al. Colloid release and clogging in porous media: Effects of solution ionic strength and flow velocity. J. Contam. Hydrol. 181, 161-171. https://doi.org/10.1016/j.jconhyd.2015.06.005 (2015).

52. Howe, K. J. \& Clark, M. M. Fouling of microfiltration and ultrafiltration membranes by natural waters. Environ. Sci. Technol. 36, 3571-3576. https://doi.org/10.1021/es025587r (2002).

53. Kjaergaard, C., Moldrup, P., de Jonge, L. W. \& Jacobsen, O. H. Colloid mobilization and transport in undisturbed soil columns. ii. the role of colloid dispersibility and preferential flow. Vadose Zone J. 3, 424. https://doi.org/10.2136/vzj2004.0424 (2004).

54. Levy, B. S. \& Chambers, R. M. Bromide as a conservative tracer for soil-water studies. Hydrol. Process. 1, 385-389. https://doi. org/10.1002/hyp.3360010406 (1987).

55. Flury, M. \& Wai, N. N. Dyes as tracers for vadose zone hydrology. Rev. Geophys.https://doi.org/10.1029/2001RG000109 (2003).

56. Radcliffe, D. E. \& Simunek, J. Soil Physics with HYDRUS: Modeling and Applications/David E. Radcliffe and Jirí Šimunek (CRC Press, 2010).

57. Korom, S. F. \& Seaman, J. C. When conservative anionic tracers aren't. Ground Water 50, 820-824. https://doi.org/10.1111/j. 1745-6584.2012.00950.x (2012).

58. Leibundgut, C., Maloszewski, P. \& Klls, C. Tracers in Hydrology (Wiley, 2009).

59. Lange, J. et al. Multi-tracer experiments to characterise contaminant mitigation capacities for different types of artificial wetlands. Int. J. Environ. Anal. Chem. 91, 768-785. https://doi.org/10.1080/03067319.2010.525635 (2011).

60. Durst, R., Imfeld, G. \& Lange, J. Transport of pesticides and artificial tracers in vertical-flow lab-scale wetlands. Water Resour. Res. 49, 554-564 (2013).

61. Dollinger, J., Dages, C. \& Voltz, M. Using fluorescent dyes as proxies to study herbicide removal by sorption in buffer zones. Environ. Sci. Pollut. Res. Int. 24, 11752-11763. https://doi.org/10.1007/s11356-017-8703-4 (2017).

62. Bork, M., Lange, J., Graf-Rosenfellner, M. \& Lang, F. Controls of fluorescent tracer retention by soils and sediments. Hydrol. Earth Syst. Sci. 24, 977-989. https://doi.org/10.5194/hess-24-977-2020 (2020). 
63. Kung, K.-J. et al. Impact of preferential flow on the transport of adsorbing and non-adsorbing tracers. Soil Sci. Soc. Am. J. 64, 1290. https://doi.org/10.2136/sssaj2000.6441290x (2000).

64. Aeby, P. et al. Fluorescence imaging of tracer distributions in soil profiles. Environ. Sci. Technol. 35, 753-760. https://doi.org/10. 1021/es000096x (2001).

65. Allaire, S. E., Roulier, S. \& Cessna, A. J. Quantifying preferential flow in soils: A review of different techniques. J. Hydrol. 378, 179-204. https://doi.org/10.1016/j.jhydrol.2009.08.013 (2009).

66. Katagi, T. Soil column leaching of pesticides. Rev. Environ. Contam. Toxicol. 221, 1-105 (2013).

67. Lobry de Bruyn, L. A. \& Conacher, A. J. The role of termites and ants in soil modification-a review. Soil Res. 28, 55. https://doi. org/10.1071/SR9900055 (1990).

68. Cerdà, A. \& Jurgensen, M. F. The influence of ants on soil and water losses from an orange orchard in eastern spain. J. Appl. Entomol. 132, 306-314. https://doi.org/10.1111/j.1439-0418.2008.01267.x (2008).

69. Corwin, D. L. Evaluation of a simple lysimeter-design modification to minimize sidewall flow. J. Contam. Hydrol. 42, 35-49. https://doi.org/10.1016/S0169-7722(99)00088-1 (2000).

70. Fernández-Pascual, E., Bork, M., Hensen, B. \& Lange, J. Hydrological tracers for assessing transport and dissipation processes of pesticides in a model constructed wetland system. Hydrol. Earth Syst. Sci. 24, 41-60. https://doi.org/10.5194/hess-24-41-2020 (2020).

71. Calvet, R. Adsorption of organic chemicals in soils. Environ. Health Perspect. 83, 145-177. https://doi.org/10.1289/ehp.89831 45 (1989).

72. Gerstl, Z. Estimation of organic chemical sorption by soils. J. Contam. Hydrol. 6, 357-375. https://doi.org/10.1016/0169-7722(90) 90034-E (1990).

73. Leue, M., Gerke, H. H. \& Ellerbrock, R. H. Millimetre-scale distribution of organic matter composition at intact biopore and crack surfaces. Eur. J. Soil Sci. 64, 757-769. https://doi.org/10.1111/ejss.12098 (2013).

74. Larsson, M. H. \& Jarvis, N. J. Quantifying interactions between compound properties and macropore flow effects on pesticide leaching. Pest Manag. Sci. 56, 133-141. https://doi.org/10.1002/(SICI)1526-4998(200002)56:2<133::AID-PS103>3.0.CO;2-N (2000).

75. Tiktak, A., Hendriks, R., Boesten, J. \& van der Linden, A. A spatially distributed model of pesticide movement in dutch macroporous soils. J. Hydrol. 470-471, 316-327. https://doi.org/10.1016/j.jhydrol.2012.09.025 (2012).

76. Thevenot, M., Dousset, S., Hertkorn, N., Schmitt-Kopplin, P. \& Andreux, F. Interactions of diuron with dissolved organic matter from organic amendments. Sci. Total Environ. 407, 4297-4302. https://doi.org/10.1016/j.scitotenv.2009.04.021 (2009).

77. Pot, V. et al. Impact of rainfall intensity on the transport of two herbicides in undisturbed grassed filter strip soil cores. J. Contam. Hydrol. 81, 63-88. https://doi.org/10.1016/j.jconhyd.2005.06.013 (2005).

78. Brown, C. D., Hollis, J. M., Bettinson, R. J. \& Walker, A. Leaching of pesticides and a bromide tracer through lysimeters from five contrasting soils. Pest Manag. Sci. 56, 83-93. https://doi.org/10.1002/(SICI)1526-4998(200001)56:1<83::AID-PS98>3.0. CO;2-8 (2000).

79. Hillel, D. \& Warrick, A. W. Environmental Soil Physics (AP Acad. Press, 2009), [nachdr. der ausg. 1998] edn.

80. Smetak, K. M., Johnson-Maynard, J. L. \& Lloyd, J. E. Earthworm population density and diversity in different-aged urban systems. Appl. Soil. Ecol. 37, 161-168. https://doi.org/10.1016/j.apsoil.2007.06.004 (2007).

81. Vergnes, A. et al. Initial conditions during technosol implementation shape earthworms and ants diversity. Landsc. Urban Plan. 159, 32-41. https://doi.org/10.1016/j.landurbplan.2016.10.002 (2017).

82. Amossé, J. et al. Patterns of earthworm, enchytraeid and nematode diversity and community structure in urban soils of different ages. Eur. J. Soil Biol. 73, 46-58. https://doi.org/10.1016/j.ejsobi.2016.01.004 (2016).

83. Hackenberger, D. K. \& Hackenberger, B. K. Earthworm community structure in grassland habitats differentiated by climate type during two consecutive seasons. Eur. J. Soil Biol. 61, 27-34. https://doi.org/10.1016/j.ejsobi.2014.01.001 (2014).

84. Singh, J., Schädler, M., Demetrio, W., Brown, G. G. \& Eisenhauer, N. Climate change effects on earthworms-a review. Soil Organ. 91, 114-138. https://doi.org/10.25674/so91iss3pp114 (2019).

85. Kazemi, F., Beecham, S., Gibbs, J. \& Clay, R. Factors affecting terrestrial invertebrate diversity in bioretention basins in an Australian urban environment. Landsc. Urban Plan. 92, 304-313. https://doi.org/10.1016/j.landurbplan.2009.05.014 (2009).

86. Deng, Y. Low-cost adsorbents for urban stormwater pollution control. Front. Environ. Sci. Eng. 14, 327. https://doi.org/10.1007/ s11783-020-1262-9 (2020)

87. Markiewicz, A., Strömvall, A.-M. \& Björklund, K. Alternative sorption filter materials effectively remove non-particulate organic pollutants from stormwater. Sci. Total Environ. 730, 139059. https://doi.org/10.1016/j.scitotenv.2020.139059 (2020).

88. Kümmerer, K., Dionysiou, D. D., Olsson, O. \& Fatta-Kassinos, D. A path to clean water. Science (New York, N.Y.) 361, $222-224$. https://doi.org/10.1126/science.aau2405 (2018).

89. Kümmerer, K., Dionysiou, D. D., Olsson, O. \& Fatta-Kassinos, D. Reducing aquatic micropollutants-increasing the focus on input prevention and integrated emission management. Sci. Total Environ. 652, 836-850. https://doi.org/10.1016/j.scitotenv. 2018.10.219 (2019).

90. Gee, G. W. \& Or, D. Particle-size analysis. In Dane, J. H. \& Topp, C. G. (eds.) Methods of Soil Analysis: Part 4 Physical Methods, vol. 5 of SSSA Book Series, 255-293 (Soil Science Society of America, Madison, Wisconsin, USA, 2002).

91. Bisutti, I., Hilke, I. \& Raessler, M. Determination of total organic carbon-an overview of current methods. Trends Anal. Chem. 23, 716-726. https://doi.org/10.1016/j.trac.2004.09.003 (2004).

92. OOECD. Test No 106: Adsorption-Desorption Using a Batch Equilibrium Method (2000).

93. Paijens, C., Bressy, A., Frère, B. \& Moilleron, R. Biocide emissions from building materials during wet weather: Identification of substances, mechanism of release and transfer to the aquatic environment. Environ. Sci. Pollut. Res. Int.https://doi.org/10.1007/ s11356-019-06608-7 (2019).

94. Lewis, K. A., Tzilivakis, J., Warner, D. J. \& Green, A. An international database for pesticide risk assessments and management. Human Ecol. Risk Assess. Int. J. 22, 1050-1064. https://doi.org/10.1080/10807039.2015.1133242 (2016).

95. R Development Core Team. R: A Language and Environment for Statistical Computing (2008).

96. Stamm, C. et al. Multiple tracing of fast solute transport in a drained grassland soil. Geoderma 109, 245-268. https://doi.org/ 10.1016/S0016-7061(02)00178-7 (2002).

97. Schindelin, J. et al. Fiji: An open-source platform for biological-image analysis. Nat. Methods 9, 676-682. https://doi.org/10. 1038/nmeth.2019 (2012).

98. Smart, P. L. \& Laidlaw, I. M. S. An evaluation of some fluorescent dyes for water tracing. Water Resour. Res. 13, 15-33. https:// doi.org/10.1029/WR013i001p00015 (1977).

99. U.S. Environmental Protection Agency. Estimation programs interface suite for microsoft windows, v 4.11. United States Environmental Protection Agency, Washington, DC, USA (2012).

100. Scientific Committee on Consumer Products. Opinion on acid red 52, 24 June 2008, European Commission (2008).

101. Bester, K. et al. Activated soil filters for removal of biocides from contaminated run-off and waste-waters. Chemosphere 85, 1233-1240. https://doi.org/10.1016/j.chemosphere.2011.07.017 (2011).

102. Zanker, V. \& Peter, W. Die prototropen formen des fluoresceins. Chem. Ber. 91, 572-580. https://doi.org/10.1002/cber.19580 $910316(1958)$ 
103. Kasnavia, T., Vu, D. \& Sabatini, D. A. Fluorescent dye and media properties affecting sorption and tracer selection. Ground Water 37, 376-381. https://doi.org/10.1111/j.1745-6584.1999.tb01114.x (1999).

104. Hensen, B., Olsson, O. \& Kümmerer, K. A strategy for an initial assessment of the ecotoxicological effects of transformation products of pesticides in aquatic systems following a tiered approach. Environ. Int. 137, 105533. https://doi.org/10.1016/j.envint. $2020.105533(2020)$.

\title{
Acknowledgements
}

We thank Kenton Stutz for his linguistic and technical corrections of the manuscript.

\section{Author contributions}

Conceptualization, methodology: M.B., J.L., M.G.-R., F.L.; investigation, formal analysis, validation and visualization: M.B., B.H., T.H., E.F.-P.; project administration: J.L., O.O., F.L.; funding acquisition: J.L., F.L., O.O., M.G.-R.; writing-original draft: M.B., B.H.; writing-review and editing: all authors; approval to the final version of the manuscript: all authors.

\section{Funding}

Open Access funding enabled and organized by Projekt DEAL. This research was funded by the Federal Ministry of Education and Research (BMBF) (02WRM1366B) in the project MUTReWa (Measures for a sustainable approach to pesticides and their transformation products in the regional water management) and by the European Union and the European Regional Development Fund (ERDF) within the INTERREG V Upper Rhine program in the project 5.3 NAVEBGO (Sustainable reduction of biocide inputs to groundwater in the Upper Rhine region).

\section{Competing interests}

The authors declare no competing interests.

\section{Additional information}

Supplementary Information The online version contains supplementary material available at https://doi.org/ 10.1038/s41598-021-86387-9.

Correspondence and requests for materials should be addressed to M.B.

Reprints and permissions information is available at www.nature.com/reprints.

Publisher's note Springer Nature remains neutral with regard to jurisdictional claims in published maps and institutional affiliations.

\begin{abstract}
(c) (i)
Open Access This article is licensed under a Creative Commons Attribution 4.0 International License, which permits use, sharing, adaptation, distribution and reproduction in any medium or format, as long as you give appropriate credit to the original author(s) and the source, provide a link to the Creative Commons licence, and indicate if changes were made. The images or other third party material in this article are included in the article's Creative Commons licence, unless indicated otherwise in a credit line to the material. If material is not included in the article's Creative Commons licence and your intended use is not permitted by statutory regulation or exceeds the permitted use, you will need to obtain permission directly from the copyright holder. To view a copy of this licence, visit http://creativecommons.org/licenses/by/4.0/.
\end{abstract}

(C) The Author(s) 2021 